\title{
Governing the ice. Ice fishing villages on Lake Mille Lacs and the creation of environmental governance institutions
}

\author{
Kristof Van Assche ${ }^{\mathrm{a}, \mathrm{b}}$, Johannes Van Biesebroeck ${ }^{\mathrm{c} *}$ and Jeff Holm ${ }^{\mathrm{d}}$ \\ ${ }^{a}$ Communication \& Innovation Studies, Wageningen University, Wageningen, The Netherlands; \\ ${ }^{b}$ ZEF/ Center for Development Research, Bonn University, Walter-Flex-Straße 3, D-53113 Bonn, \\ Germany; ${ }^{c}$ Economics Department, University of Leuven, Naamsestraat 69, Leuven, 3000 Belgium; \\ ${ }^{d}$ Minnesota State University, St. Cloud, USA
}

(Received 21 June 2012; final version received 14 March 2013)

\begin{abstract}
We identify four choice dimensions that determine the configuration and evolution of governance: formal-informal institutions, network-central steering, local-scientific knowledge and representation-participation. Choices on one dimension affect choices on the other dimensions, which naturally leads to historical dependency. We integrate these insights in a model of governance evolution that revolves around actor/ institution configurations and power/knowledge configurations. In a case study of ice fishing villages on Minnesota's Lake Mille Lacs, we investigate one specific set of couplings between the choice dimensions. As we can study the local ice fishing tradition from its very beginning, the evolutionary paths of technology and institutions provide insights into how choices were made along the different dimensions and how they interacted. The case study illustrates how to apply the model, but also contributes to its further development as it draws attention to possible extensions: concepts of scale and identity.
\end{abstract}

Keywords: institutions; power/knowledge; governance evolution; ice fishing

\section{Introduction: interrelated choice dimensions}

We believe that two aspects of governance are key to its understanding. Governance is a multi-dimensional process and it is always shaped by the history of governance. This has been well understood, but we want to highlight that these two aspects are intrinsically related. Drawing on several literatures on governance, and especially on natural resource governance, we illustrate the importance of four dimensions: types of institutions, forms of democracy, forms of steering, and knowledge mobilised. Each dimension we understand as a choice. Alternative positions are possible, and, at least at certain points in the governance evolution, these positions can be chosen.

To make the framework more concrete, we can distill from the same literature the following distinctions along the different choice dimensions: formal or informal institutions, representative or participatory democracy, centralised or network steering, and scientific or local knowledge. Therefore, governance is a combination of choices along these dimensions but also constrained by previous choices, creating path dependencies. Our focus is the manner in which positions taken on different choice dimensions affect each other. This influence is not instantaneous, but develops over time as agents react to the environment they confront. The prevailing position on one dimension makes some positions on other dimensions impossible or less attractive. It

*Corresponding author. Email: jo.vanbiesebroeck@kuleuven.be 
leads to a dependency in environmental governance that has often been overlooked in the literature. Usually, positions on one dimension (e.g. degrees of participation or social learning or formality) are analysed separately to assess governance arrangements (see, for example, Davies 2002; Bulkeley and Mol 2003; Helmke and Levitsky 2004; Margerum and Whitall 2004; Easterly 2006; Singh, Pretty, and Pilgrim 2010).

We first present a conceptual governance model to understand the interrelation of the four choice dimensions that structured the evolution in our case study. The construction of the model proceeded in several steps. First, we distilled four dimensions from the natural resource governance literature and established potential relations between them. Next, we conducted the case study, which confirmed the importance of the four dimensions but also drew attention to the contingency of both the set of dimensions and their linkages, a contingency that stems from the evolution itself. In other words, the case also showed that the relevant dimensions could have been different and that they could have affected each other in different ways. This made it possible to improve the model and arrive at the version presented below. Several iterations of observation and theory building were needed.

In the case study, we reconstruct the development of ice fishing villages on Minnesota's Lake Mille Lacs, where no one owned the ice and all players and institutions had to be invented. Our main objective in describing the emergence of ice fishing villages is to first illustrate that choices along different dimensions are inherently interdependent and, second, to develop insights into the nature of the interrelations. This, in turn, enables us to make inferences about the contingent nature of the dimensions themselves. The case study not only provides insights into the linkage of dimensions and their co-evolution, it also suggests that alternative courses are possible. For example, the observed mechanisms make it possible that some dimensions become de-coupled over time from the governance evolution, or lose their relevance. Therefore, we should understand the dimension sets themselves, not only the couplings between them, as evolutionary products which can vary by situation.

The recent development of the fishing villages makes it possible to sketch the entire evolution, from the beginning to the current situation. It also allows us to draw upon the direct experiences of the actors that shaped governance through extensive interviews. The virtual absence of historical arrangements makes a direct link with the theory possible. Since not much happened before the starting point of our analysis, and no institutional and organisational structure existed, we can reconstruct the whole evolutionary path. It makes the case an interesting place to develop an evolutionary governance theory. In the development of our model, and the analysis of the Mille Lacs case study, we explicitly do not reduce the issue to one of resource management, with fish as the only resource. The lake enables a wide variety of experiences that are appreciated and gave rise to communities that required many aspects of governance.

Some of the environmental governance literature has already considered multiple dimensions. Ostrom's famous IAD model is one example (e.g. Ostrom 1990, 2005), and the literature on socio-ecological resilience and adaptive governance provides another example (e.g. Allen 2001; Olsson, Folke, and Berkes 2004; Davidson-Hunt 2006; Booher and Innes 2010; Newig, Gunther, and Pahl-Wostl 2010). The specificity of our approach, and its added value, resides in the combination of existing literatures on the four dimensions, and the re-articulation of key insights from these perspectives in a multi-dimensional model that is inherently evolutionary. As it is a new approach, more testing and refining will be required in the future.

The idea of governance arrangements as the outcome of path dependent historical processes is already present in institutional economics, in the more contingency-oriented 
versions of North (1990, 2005), Greif (2007) and Acemoglu and Robinson (2012). The coupling and interrelation of choice dimensions is well illustrated by the work of Arun Agrawal on how functional environmental governance arrangements can evolve based on, and producing, a highly diverse set of couplings (Agrawal and Gibson 1999; Agrawal and Benson 2010; Agrawal and Chhatre 2011). In the field of industrial organization, Milgrom and Roberts (1990) illustrated how choices on one dimension affected the costs and potential benefits of alternative positions on a second dimension - they wrote about complementarities. Acemoglu and Robinson (2012) demonstrated how economic and political institutions shape each other in institutional development. Scientific knowledge can serve as fuel for the development or codification of specific institutional configurations (Folke et al. 2005; Easterly 2006; Booher and Innes 2010).

In the remainder of the paper, we first introduce our model of governance and provide references to the relevant literature. This is followed by sections on methodology and a historic overview of the ice fishing villages. In Section 5 we discuss the development of technology, rules, and organisations, which introduces the set of actors involved and their interactions. In Section 6 we focus more explicitly on the four choice dimensions and their coupling. We conclude with a discussion of the significance of the case study for a more general model of natural resource governance.

\section{A conceptual model of governance}

We define governance as the making of decisions that bind a collective or a community to rules and roles (cf. Easterly 2006; Acemoglu and Robinson 2012). We see natural resource governance as the governance of natural resources, of places where resources are found or that are considered resources themselves, and governance of behaviour towards each other in situations or places of resource use. Defined in this way, at the same time, governance inherently requires the involvement of actors and institutions as well as the reliance on power and knowledge.

In line with North $(1990,2005)$, we define institutions as man-made constraints that structure political, economic and social interaction. They are the product of evolution and consist of both formal and informal constraints. They emerge in processes of co-evolution as tools of co-ordination between actors. Two related concepts will be introduced shortly. In line with Putnam (1993), we define democracy as a form of co-ordination of political decisions, i.e. decisions intended to bind the community. Democracy has many forms, but theoretically they share that each member has a say in collective decision making, either directly (participation), or indirectly (representation). Its effect in a community depends on the embedding in informal institutions, some of which are the result of slow evolution, some of which of rapid adaptation. In line with Luhmann (1990), we define steering as the attempts of politics to shape the behaviour of individuals and groups by means of problem definition, goal setting and policy implementation. The forms and success of steering hinges on distribution of agency; if different sets of actors participate in, are excluded from, or elude political decision making, forms of steering and steering ambitions will differ.

The relevant community can be each group of actors and institutions that shares a location and shows aspects of interdependence in the form of interdependent configurations of roles and rules (Greif 2007; Van Assche et al. 2011). The nature of the decision making (Eggertsson 2005; Kernick 2005) and the formality of organisation (Czarniawska 2008) are two key defining factors in any type of institution. The source of their knowledge (Fernandez-Gimenez, Ballard, and Sturtevant 2008) and their place in 
the web of interactions (Hahn 2011) are two factors that distinguish the roles of different agents.

Actors and institutions shape each other, so one can speak of actor/institution configurations. Many contributions in institutional economics illustrate a gradual consolidation of rules of behaviour into explicit laws (North 1990, 2005; Eggertsson 2005; Greif 2007). Given time, dedicated formal institutions tend to emerge to lower transaction costs (Williamson 1981). In their absence, repeated interactions and individual reputations are crucial elements that sustain activity. Association with an identifiable group is a semi-formal way that strengthens such mechanisms (Easterly 2006; Van Assche et al. 2011). Within a group, roles evolve that help to stabilise the rules. Greif, Milgrom, and Weingast (1994) illustrated the enforcement of implicit trading rules by the medieval merchant guilds that made trading between anonymous parties possible even when the need for credit or quality assurance made payoffs time-dependent. Subsequently, the emergence of a formal banking system and government regulations covering liability and transfers of property rights extended the viability of anonymous trading (Milgrom, North, and Weingast 1990).

Knowledge and power are intrinsically entwined as well. Power shapes the forms and uses of knowledge in a governance process, and conversely, knowledge embedded in governance moulds the evolution of power relations (Hajer and Wagenaar 2003; Czarniawska 2008). One can never entirely subtract the influence of power on knowledge and vice versa (Davies 2002; Ledeneva 2006), and for that reason we speak of power/ knowledge configurations. In turn, these configurations influence the formation and evolution of rules and roles, of institutions and actors. Of the four choice dimensions we consider, the formality of the institutions and the nature of decision making or steering appear to be particularly important in the restraining and the assigning of power (cf. Margerum and Whitall 2004; Klijn and Skelcher 2007).

The word 'configuration' directs attention to a structure of relations, where none of the elements can be understood without reference to the others. We need to complement this aspect of structure with an aspect of process; in the configurations, nothing is entirely stable. Power and knowledge are continuously transforming each other, and the same applies to actor/institution configurations.

If power and knowledge shape each other, and actors and institutions shape each other, then these two processes can form the heart of an evolutionary governance model. The model can link together the choice dimensions that we distilled from the literature. In Table 1 we show the four dimensions that we found to be most important for our case study. Already at this point in theory construction it appears a logical possibility that different evolutions and/or governance requirements could lead to different dimensions being important. While power/knowledge and actor/institution interactions underpin the linkage between dimensions, nothing in the theory prevents the emergence of other dimensions, e.g. spanning different versions of network steering, different authoritarian forms of organisation or competing religious explanations. Therefore, the case study by no means excludes the possibility that other dimensions prove to be important in other cases. More interesting for us, and the key focus of our contribution, is the interrelationship between the different dimensions and the nature of these relations. In our case analysis, we therefore first discuss each choice dimension separately and then dissect the relations between them, which highlights that the underlying configurations - actor/institutions and power/knowledge - are the conduits of influence between the dimensions.

We will illustrate, in particular, that changes on one governance dimension are likely to influence the change process taking place in the configurations and trigger changes 
Table 1. Choice dimensions for institutional formation in environmental governance.

\begin{tabular}{|c|c|c|c|}
\hline \multirow{2}{*}{$\begin{array}{l}\text { Choice dimensions } \\
\text { Institutions: }\end{array}$} & \multicolumn{2}{|c|}{ Polar positions } & \multirow{2}{*}{$\begin{array}{l}\text { Representative references } \\
\text { Eggertsson 2005, Farrell-Heritier } 2003 \\
\text { Greif 2007, Helmke-Levitsky } 2004\end{array}$} \\
\hline & Formal $\leftrightarrow$ & Informal & \\
\hline Steering: & Central $\leftrightarrow$ & Network & $\begin{array}{l}\text { Allen 2001, Hahn 2011, Kickert et al. } \\
\text { 1997, Newig et al. } 2010\end{array}$ \\
\hline Democracy: & Representative $\leftrightarrow$ & Participatory & $\begin{array}{l}\text { Anderson 1999, Bulkeley-Mol 2003, } \\
\text { Klijn-Skelcher } 2007\end{array}$ \\
\hline $\begin{array}{l}\text { Knowledge } \\
\text { mobilization: }\end{array}$ & Scientific $\leftrightarrow$ & Local & $\begin{array}{l}\text { Berkes 2009, Davidson-Hunt 2006, } \\
\text { Margerum-Whitall 2004, Verdery } 2003\end{array}$ \\
\hline
\end{tabular}

elsewhere in the configurations. In turn, this can cause more visible changes, namely changes in other choice dimensions. For example, changing forms of steering can reshape the roles of knowledge, which impact power distributions, which affects the roles of (in) formality, which in turn has effects on the roles of actors and thus on the participation/ representation balance, etc. ad infinitum. An exogenous change in circumstances that prompts a direct change in position on one dimension will thus have repercussions for the positions on other dimensions, because it intervenes in the dynamics of underlying power/knowledge and actor/institution configurations.

The two configurations connect the four dimensions in the manner of an infrastructure. The processes that continually reshape the configurations alter the pattern and intensity of linkages between the dimensions. One result can be that certain dimensions become decoupled from the rest, become less affected by governance evolution, and thus less relevant for modelling such evolution. Conversely, it is possible that a new choice dimension emerges as relevant and is entwined with the others. For example, before science existed it did not structure a choice dimension in a polarity with local knowledge.

The interaction and co-evolution of the different choice dimensions is important, because some positions fit together more naturally than others. Milgrom and Roberts (1990) analysed this formally in terms of complementarities. The marginal benefit of adopting one practice, e.g. varying wage with performance, is higher if a second practice is adopted as well, e.g. delegating decision-making authority to the worker. In our case, one can logically deduce that a highly centralised system can more easily rely on formal institutions, and that both are more likely to emerge in a form of democracy heavily emphasising representation.

The outcome of such complementarities of positions on different choice dimensions in our particular case study is indicated in Table 1. With some simplification, one can view the observed governance of ice fishing on Lake Mille Lacs as the combination of four rather polar choices on each of the choice dimensions. In the analysis below we discuss how these different choices have reinforced and stabilised each other over time. In contrast, when the Minnesota Department of Natural Resources (Mn-DNR) introduced strict fishing quotas, they used a governance approach that had evolved independently and was more formal, central, representative and scientific. The difficult interaction with the existing local governance system will also be discussed below. 


\section{Methodology}

The case study is based on fieldwork in the winters of 2008, 2009 and 2010, with some additional data gathering in early 2011. In total, we interviewed 60 people (some of them several times, leading to 72 interviews overall). The interviews were semi-structured, ranging from 45 minutes to 3 hours, with fishermen of all ages, resort owners and people working in associated businesses, such as restaurant and bar owners, fishing guides and builders of equipment. We also interviewed people working in tourism and fishing promotion, local government officials, journalists and employees of the Mn-DNR. Interviews took place in ice shanties, in bars and restaurants, at people's homes and businesses. Other stakeholders were identified in the following manner: the importance of resort owners was clear from the start, so we tracked current and previous owners. We relied on their judgement, as well as that of local writers, journalists and old fishermen, to further identify key players and key informants. From there on, we followed a snowball method to fill in gaps (Ledeneva 2006).

Interviews were transcribed and coded for roles, institutions and narratives of evolution. In the coding of the interviews we identified various positions on the four choice dimensions and recurrently tested whether these four dimensions were indeed the most relevant ones to explain the observed evolutions. In subsequent steps we investigated the manner in which the choices in different dimensions related to each other. In the research team we discussed initial findings and hypotheses and took them back to the field (and the archive) for testing and refining.

Further, we studied the archives of the local newspaper, the Mille Lacs Messenger (1937-2009), analysed writings by local authors (Fellegy 1973, 1990; Stark and Berglund 1990; Lindner, Stange, and Genz 1991; Lyback 1996; Breining 2003; Nordstrom 2007; Breining and Kennedy 2008), old maps and tourist brochures, a few fishermen's diaries, and we collected Mn-DNR reports (going back to the 1920s) and statistics which underlie the tables and figures below.

\section{Ecology and history of ice fishing on Lake Mille Lacs}

Because the specific features of Lake Mille Lacs had profound implications on the formation of the ice villages, we briefly sketch its geology and ecology. The lake is located in central Minnesota (see Figure 1). The lake bottom is generally flat (at ca. 40 feet; Smith 2001), but a number of shallower zones occur which locally are called 'reefs.' Two species that proved important for ice fishing are abundant: walleye (or pikeperch) and northern pike. The latter stay closer to shore, mostly hunting shallow weedy areas, while walleyes stay in the deep, or hunt along the edges of the reefs (Fellegy 1973, 1990; Lindner, Stange, and Genz 1991). For the walleyes, the combination of deep water, reefs, and some sandy and gravelly beaches (spawning habitat) proved a winning one.

It was the walleye that made Lake Mille Lacs famous. With the coming of a railroad and the construction of highway 169 in the 1920s, the lake started to attract anglers and their families from Minneapolis-St. Paul and from many other states (Fellegy 1990; Mille Lacs Messenger). Lake Mille Lacs became known as the 'walleye factory', and small resorts for summer fishing sprung up all around the lake. The size of the lake, the winds and the difficulties in navigation (in the absence of clear landmarks) made it easier for resort owners with bigger boats to sell their services as fishing guides.

Before consolidation of the resorts started in the 1960s, a major change took place on the winter lake. Ice fishing had been practised by native Americans for centuries, and the 


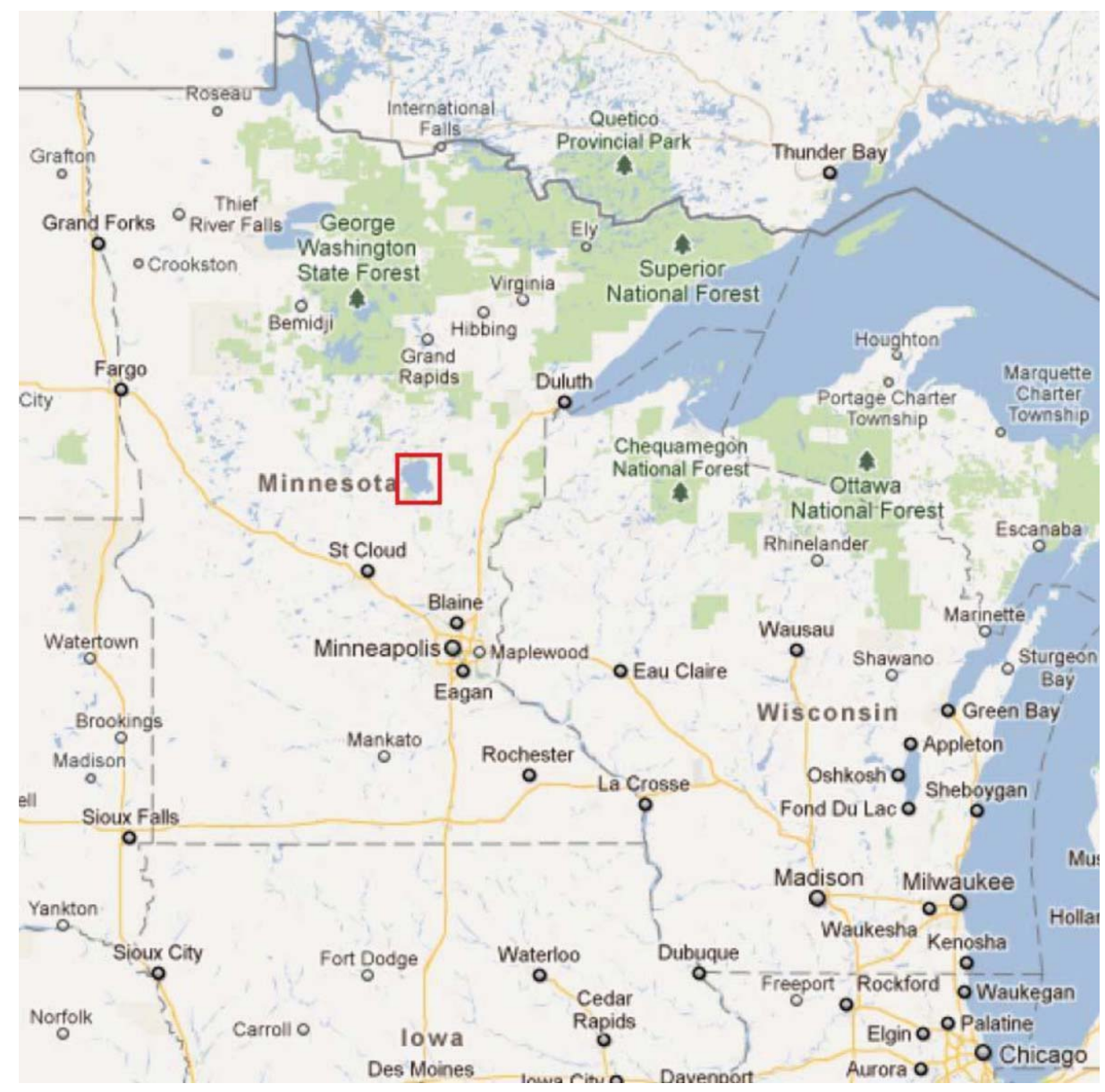

Figure 1. Location of Lake Mille Lacs, MN (indicated by the square).

Source: http://maps.google.com

Scandinavian immigrants in the area also brought their ice fishing traditions from Europe (Breining and Kennedy 2008). Since the early 1950s, Lake Mille Lacs was actively promoted as a winter destination (Mille Lacs Messenger). By the late 1950s, some form of ice fishing industry had emerged, with competitions, festivities and hundreds of ice shanties. The shanties were a new development, not part of either native American or Scandinavian ice fishing traditions. ${ }^{1}$ Resort owners looking for winter income often built them, rented them out, and promoted the reinvented sport (Lyback 1996; interviews).

During these times, few people dared to venture far on the lake. Ice fishing was originally linked to northern pike, the species usually targeted in older traditions (Mille Lacs Messenger; interviews). That meant staying close to shore, and using a spear in a tiny dark house with a large hole cut in the ice. As long as fishermen spent the nights at the resorts, there was no need to create villages; keeping a distance from each other was preferable (Lindner, Stange, and Genz 1991). Since fishing was close to shore, no real ice roads or other infrastructure was needed. Staying over in the tiny dark houses was impossible anyway, further obviating the need to develop more infrastructure on the lake itself. 


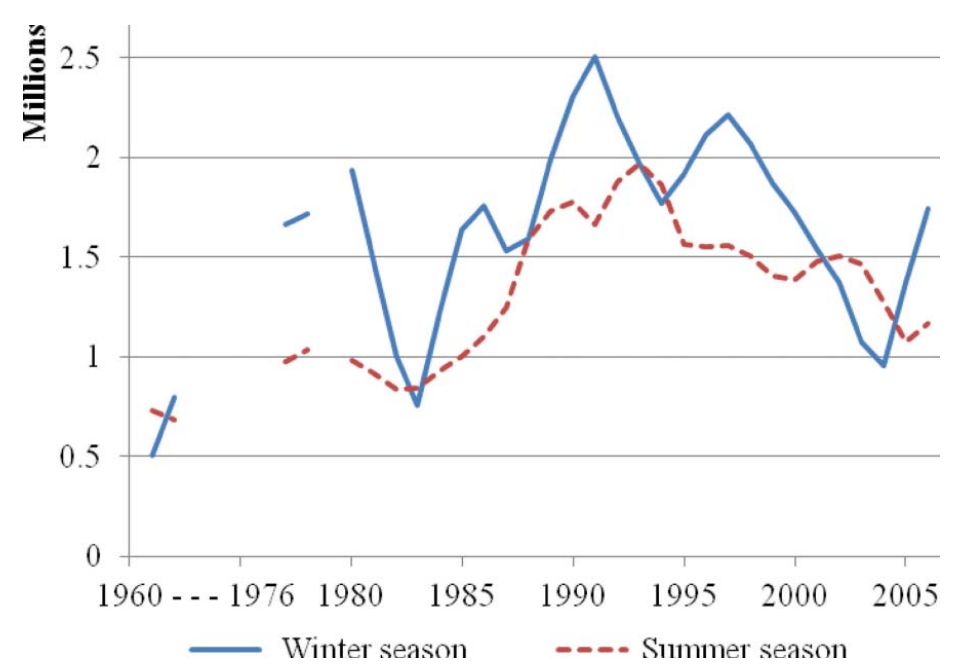

Figure 2. Evolution of the total number of hours devoted to fishing on Lake Mille Lacs.

Notes: Statistics are a three-year moving average, expressed in millions of hours. Source: Mn-DNR Mille Lacs Creel Census annual performance reports.

The move to walleye-fishing made the ice fishing villages possible and useful. But there was no institutional arrangement to manage risk and resources in a manner that was economically feasible. There was a need for technological and institutional innovations for ice fishing to thrive in the harsh landscape and climate. We discuss the main technological, organisational and institutional innovations next, but first give a quantitative summary of ice fishing on the lake.

Figure 2 shows the evolution of total fishing hours logged on the lake between 1961 and 2006. Continuous data are only available for the period 1980-2006, but partial information for the periods 1960-1961 and 1976-1977 extends the picture. The solid line designates the winter season, generally running from December to April, and the dashed line stands for the summer season, primarily May to October. Because the number of hours fluctuates dramatically over time, especially as the length of the winter season depends on ice conditions, we depict a three-year moving average.

In terms of total hours devoted, ice fishing is somewhat more popular than summer fishing. This is in spite of a total walleye catch over the summer season that is on average approximately five times as large as the winter catch. In years with good ice conditions and a long winter season, total ice fishing hours are 50-100\% higher than summer hours. ${ }^{2}$ Figure 2 also shows that fishing has gained popularity since the 1960 s, with a temporary decline in the late 1990 s potentially related to the introduction of harvesting slots for walleye (starting in 1997).

\section{Evolution and innovation}

In the case of the ice fishing villages on Lake Mille Lacs, the evolution of governance is marked by a high degree of innovation. We demonstrate how the institutional configuration supported technical innovation, while some technical novelties reshaped institutions. While none of the participants in, say, 1960, could envision the current situation, one can speak of a shared goal, the development of the ice villages. Once that 
development option dawned on the actors (cf. interviews), a pattern of interactions developed where various obstacles were identified and overcome. In the following sections, we will outline three lines of innovation: technical, organisational and institutional. Knowledge mobilisation and the formation of actors and institutions are linked to our basic model. We will indicate how these lines interweave. In Section 6 we then return to the four choice dimensions, analyse them in our case study and indicate how they interrelate.

\subsection{Technical innovations that made ice fishing possible}

To get to the middle of the lake and target walleye, a different mode of transportation and spatial organisation is required than for fishing near-shore. An old resort owner/fishing guide remembered that, "in the fifties, when I was far out on the ice, you could see nothing and nobody; it was beautiful - and good fishing". In the 1960s, cars were considered reliable enough to drive for miles on the ice and to stay out there (Lyback 1996; interviews; no cars or roads mentioned in Dalrymple 1948). Resort owners had devised ways to build roads on the ice, custom-building snow ploughs and attaching them to their trucks. They had also figured out how to bridge cracks in the ice, or patches of unsafe layered ice, by means of metal bridges. Meanwhile, the same resort owners hired people to patrol their resorts constantly, looking for cracks in the ice and people in trouble. ("Not easy to find those guys in the beginning; you had to train them", an old resorter remembered)

Fishing far out on the lake only made sense if one could stay for several days, and this required reinventing the shacks themselves. Resort owners owned and rented out shacks and gave them a spot on their ice territory, but they also rented out spots to owners of private houses. Resort and private owners learned from each other, and over the years, they found new solutions for heating, cooking, hygiene, sleeping and entertainment ("We were always looking what the other guys were doing", remembered one, adding "we had to do something, we had to invent everything ourselves"). The houses had to be dragged out onto the lake, and early innovators tied skis to the houses. Both the skis and the power of the vans limited the size of the house, but stronger trucks and (in the last 10 years) hydraulic systems removed those limitations (Nordstrom 2007; Breining and Kennedy 2008).

Other technologies were involved. The quality of the drills ('ice augers') was improved drastically. Swedish ice drills were the first models, and some are still imported. Savvy individuals quickly started experimenting with mechanical drills, powered by engines from old lawn mowers and washing machines. An old fisherman remembered: "we tried everything, and some of it exploded or just stalled. Still, fun to try". Then, in the 1970s, a specialised industry developed, building ever more powerful drills dedicated to ice fishing. The fishing poles and tackle had to be reinvented for use in the confined space of a shack and in a small hole (Fellegy 1990; Lindner, Stange, and Genz 1991). Private innovators here also paved the way for a regional industry, and the initial piece of wood with a line and sinker quickly evolved into a wide array of short poles and various tackle. An old fishing guide stated: "nobody was proud of traditional tools. If you were using a stick you were considered backward or just plainly stupid".

Finding the fish was not easy. Because of the difficulties and the cost of organising, and because of the interpretation of the walleye ecology and its dependence on reefs, it was hard to move the shacks often. Underwater cameras began to be used in the 1990s, but the major innovation came from a Lebanese-American plumber from St Paul, MN, a 
talented fisherman and a gifted engineer, who obtained a Japanese submarine sonar, and re-engineered it for the purpose of locating fish under the ice (interviews). Again, a business developed and the Minnesota firm Vexilar is still the leading firm in the industry of electronic ice fishing aids. ${ }^{3}$

Navigation posed other technical obstacles. In the 1950s, 1960s and 1970s, knowledge of the underwater landscape was at a premium, in a large lake with very few features to make way-finding easier. "People didn't go out very far in winter, because they were not sure where to go or what to look for", stated an old fisherman. Fishing guides with years of summer experience had navigation strategies enabling them to remember the relevant facts for winter fishing (Fellegy 1973; interviews). Very precise interpretation of the horizon in different directions was a prerequisite for the pioneers, and changes in the horizon - removal of buildings or trees - could create confusion. ${ }^{4}$ An old resorter stated: "finding the mudflats in summer was hard enough, but in winter ten times harder". In the 1980s, the first maps of the underwater topography appeared, and the publication of the 'Walleye whiffer' (1987) by the owner of a local bait shop, a map based on the collective experience of many fishing guides and early electronic equipment, was a landmark in ice navigation.

After 2000, GPS handheld devices became cheaper and widespread. Several regional firms specialised in the development of datasets for ice fishing, with detailed information on the underwater topography, and functions to easily remember and share good and bad fishing spots, tricky cracks and other information (a practice anticipated in Smith 2001). The internet magnified and multiplied the available information, and resort owners, fishing guides and fishermen participate in discussion rooms, write blogs and elaborate in much detail on the qualities of the lake and of this or that fishing spot or piece of equipment.

\subsection{Organisational innovations}

The technical developments are entwined with organisational and institutional innovations, and we argue that it is the combination of them that made ice fishing villages possible. Because of the underwater landscape, with the edges of the reefs and mudflats as favourite spots for the walleye, it was optimal to cluster the fish houses there ("Prime real estate", according to an old resorter). Catch rates are much lower in the winter season than in summer and good fishing spots are a scarce resource. Consideration of both risk and economic efficiency - the cost of road building, maintenance and patrolling - reinforced the idea of clustering, leading to the appearance and, later, the social practices of a neighbourhood. Forced to interact on the ice where the law did not assign any property rights, and many existing laws were not enforced, the participants developed informal rules of collaboration.

Among the actors, we first need to mention the resorts. The original 'mom and pop' resorts did not have the capacity to create the ice fishing villages described. Looking for winter income, they, together with experimenting fishermen, de facto created what is now known as ice fishing (Fellegy 1990; Lyback 1996; interviews). The resort owners, their guides and their clients were engaged in a process we could call social learning (see for example Berkes 2009), which at the same time was a search for economic opportunities. That search led them to the discovery of a form of ice use that would only work if they increased their scale. Surviving summer resorts were usually the ones that were successful in the more capital-intensive winter operations ("We need the winter fishing, no way around it", said one of the younger resorters). 
Second, there are the bait shops around the lake. Traditionally, these were meeting points, places to buy equipment, to get the latest information on the conditions of the ice and to get up-to-date stories of fishing success and failure. As exemplified by the Walleye Whiffer (map), the bait shops were also places of innovation, as nodes in overlapping networks of communication. Often, the shop owners were involved in other roles in the ice fishing business, either as co-owners of small resorts, as guides or bar owners. An old fisherman remembered: "the bait shop used to be the place to be, a place to hang out, learn about the ice, the fish and nifty equipment".

Third, there is the network of businesses that developed and produced the necessary equipment. Virtually everything had to be invented or reinvented, from shacks to augers to fish finders and tackle. These businesses should be considered as part of the network of learning and innovation in Minnesota that made this form of fishing possible. The people working there, including the managers and owners, are usually ice fishermen themselves. They go to Mille Lacs regularly, know the fishing guides, resort owners and bait shop owners, and know about the latest complaints and inventions by individual fishermen. They are also in close contact with the people in other businesses in the industry, and try to build on innovations in these adjoining niches. A resort owner said: "we know these guys, and we're proud of them. Plain fishermen, from here, building a successful business out of ice fishing".

Conspicuously absent is government, both local and state government. In most small towns surrounding the lake, the network of fishing-related businesses has an influence on local politics. This partly explains the minor government involvement. Another element is the already mentioned unique character of the activity, hard to compare with other things, hard to regulate. A few younger fishermen, with some old guys who agreed, said: "crazy, isn't it, what we're doing here? Nobody understands, but we love it".

One government actor does play a significant role. In Minnesota, lakes are state property. The Mn-DNR is responsible for enforcing the regulations regarding the exploitation of natural resources. Officially there can be no private property of portions of the ice. The consensus among the stakeholders interviewed was that the Mn-DNR is responsible for everything happening on the ice, because it is all covered under the heading of 'resource use' (and use conflicts or accidents). However, de facto, the DNR does not have the resources to enforce all types of laws on the ice when it houses a city-size population.

\subsection{Institutional developments}

An essential factor enabling institutional innovation in this legal vacuum is the tightly knit network the resort owners operate in. We refer to the mixed network of resort owners, fishermen, guides, businesses and local governments who see it as a shared goal to maintain the ice fishing on Lake Mille Lacs. This makes it a shared responsibility to minimise risk, to 'optimise the experience for all' and to guard the image of the lake and the activity. In other words, the same network that catalysed the technical innovations that made ice fishing villages possible, worked out institutional arrangements that sustained them.

We argue that the basis is a perceived property right by the resort owners. The informal rights evolved in a situation of competition between resort owners over frozen expanses, where initially no property rights were recognised (old respondents speak of a 'free for all' before the 1960s). All actors know that there is no legal basis, but all agree that the only way to maintain the industry is operating on the notion that the resort 
owners have some sort of property rights on the ice (Ellickson 1991). ${ }^{5}$ This implies that it is accepted by everyone that resort owners can rent out spots on the ice to fishermen, and that they can ask entry fees for cars on the ice. A local journalist stated: "that's the way it is. Politicians know it's not strictly legal, but they need to keep the business in town, and they're probably fishing themselves". Entry fees are possible in practice because access points, the starting points for the ice roads, are controlled by resorts owning the shore land there. In interviews it transpired that that these fees are widely accepted, since it is necessary for resorts to invest in ice roads, equipment and safety.

The situation of resort owners investing in road building on the ice, where they have no formal property rights, and fishermen paying them for access even though they are not legally required to, can be viewed as an example of a Nash equilibrium in a repeated (non-co-operative) game. The observed outcome is supported by strategies with fairly obvious off-equilibrium actions. If the resort owners would not build the roads one year, fishermen could be expected not to show up anymore next winter, depriving resort owners of current and future income. If fishermen would not pay for road use, resort owners could be expected not to build ice roads anymore the next year and the industry would cease to exist. The industry is in a fragile equilibrium where owners build roads because fishermen have come to expect a reliable ice fishing infrastructure, and they are willing to pay for access today because they want to keep fishing in the future.

Anything that changes the present valuation of the expected future benefits can be expected to change behaviour today. The actors' assessment of the likelihood that the current equilibrium will continue is an important factor in their implicit discount rate. In particular, factors that raise a resort owner's expectation of future exit from the industry lowers his incentive to build an ice road today. Two such factors are the spread of snowmobiles, which provide mobility on the ice without being dependent on the ice roads, and the pressure on fish stocks and subsequent tightening of harvest restrictions by the Mn-DNR. ${ }^{6}$ An equilibrium in a repeated game can easily become unhinged if expectations of future compliance with the equilibrium strategies changes.

The perceived ownership of villages by resort owners does not only sustain their role as road builders, but also their role as conflict mediators and enforcers of informal law. Both parties in a dispute, e.g. over fishing spots or inappropriate use of ice roads, consider the owner to be the one in charge, "you better listen to those guys", some old fishermen agreed. The owners have an investment at stake and have a clear interest in the future success of the ice fishing industry, but the position of authority can only be understood against the background of a broadly shared investment in the future of ice fishing. All parties agree, even in conflict situations, that they are interdependent, collectively responsible for survival of the activity and that giving special powers to the resort owner is the only way to stabilise the game. The owners have the advantage of others being more dependent on them on the ice ("Probably not much would happen here without them", an old guide stated). The inherent danger of this frontier activity makes the specialised knowledge and experience of the resort owner highly valuable to participants. They also have easier access to the tight network mentioned earlier, a source of further knowledge and experience in difficult situations. Resorts can inform people how to drive on the ice, how to manage their households on the ice (including 'where and how to pee').

Informal environmental regulations cover issues of littering, dead fish and hygiene. Zoning, parking and density rules are accepted as implied by the layout of roads and neighbourhoods. Traffic regulation focuses on speed, since high speeds on ice, even very thick ice, create dangerous wave movements. In contrast with the situation on shore, no 
binding speed limit applies. This is an example of the advantage of flexible informal institutions. Even more so than on regular roads, the optimal speed limit is a function of weather conditions, the state of the ice and driver experience. Rather than impose fixed limits, which would invite enforcement problems and questions of legitimacy, there are indicative speed limits and resort owners take responsibility to personally address perceived speeders.

\section{Analysis of choice dimensions}

The previous section outlined three interrelated evolutions that shaped governance of the ice villages: intense knowledge mobilisation leading to new technologies, and rapid development and mutual constitution of actors and institutions. It was the interplay of these forms of innovation that made the villages possible. Now, we return to the four choice dimensions of the model. We discuss each dimension separately, but highlight implications of choices on one dimension for options in the others. This interplay is further illustrated by contrasting the local governance with the approach taken by the Mn-DNR when instituting catch limits.

The way in which we have used the model to integrate observations from the case study into a better understanding of the emerging governance system on the ice is illustrated in Figure 3. In the case of ice fishing on Lake Mille Lacs, local experimentation proved crucial for the development of key enabling technologies and appropriate forms of organisation, as described in Section 5. The way these particular processes evolved culminated in mutually consistent positions on each of the four choice dimensions. We indicate, for both technology (on the left) and organisational form (on the right), elements that help to identify the choice that emerged on each dimension. For example, the need to cope with a unique and extreme environment, in terms of climate and ecology, required a heavy reliance on locally developed and customised technology (local knowledge).

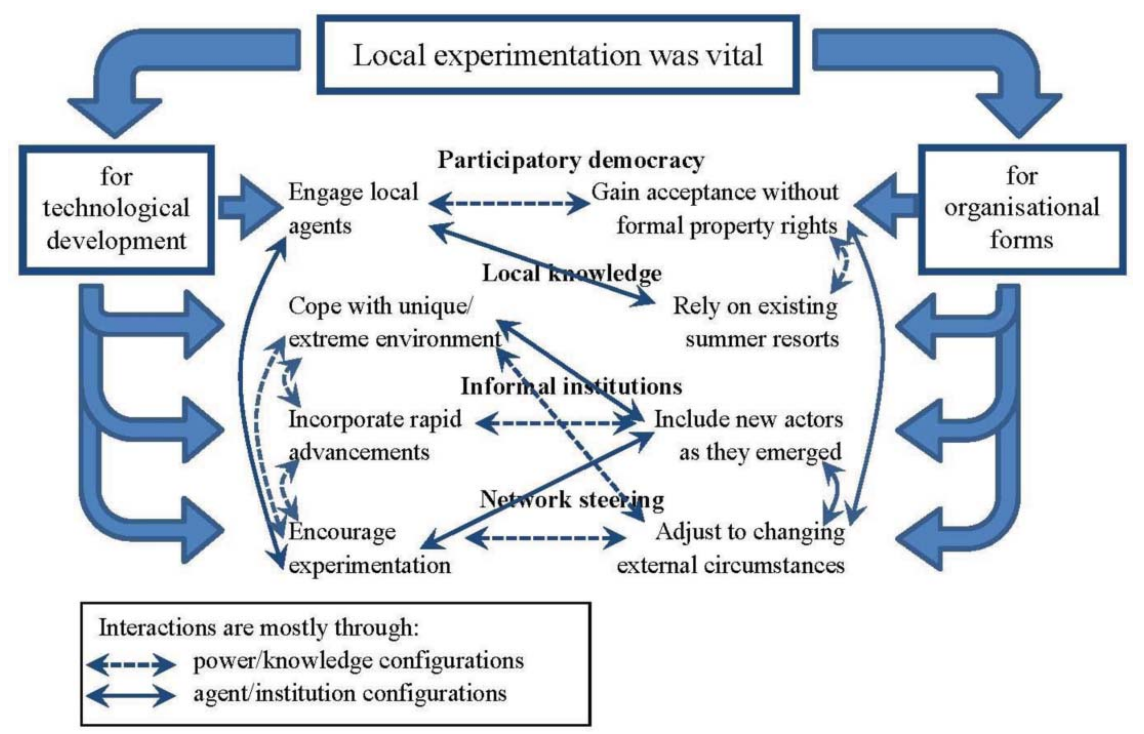

Figure 3. Example of how to incorporate observations from the case study in the model. 
Effective leveraging of local knowledge was facilitated by a decentralised or network form of steering that encouraged experimentation. To engage local agents in this process, decision making was highly participatory, with little explicit communication of rules. Given rapid advancement in technologies and thus the constraints faced by agents, an informal organisation proved most adaptable to the changing circumstances. These and other interactions between the positions taken on each choice dimension are indicated in Figure 3 by the arrows. We distinguish between those that occur mostly through power/ knowledge configurations (dashed lines) or through agent/institution configurations (solid lines).

\subsection{Formal versus informal institutions}

The informal rule that 'formal ownership of shore land and of a business there forms the basis of informal but enforced ownership of areas on the ice' was a central institution. Informal ownership further conditioned development in the direction of informality in other areas of regulation (Verdery 2003; Rosen 2008; Van Assche et al. 2011). Developing an area in front of your door gave a right to keep it, a claim of the first user, and developing further out extended those rights. This was important, as owners experimented and made investments to accumulate knowledge and gain experience about what worked and what did not, knowing that any discovery would pay off for many years (Keen, Mahanty, and Sauvage 2006; Newig, Gunther, and Pahl-Wostl 2010). The informal rule minimised the risk that after discovering a good fishing reef one year, a competing resort owner would swoop in at the start of the next season and pre-empt them from putting fishing houses on the same spot again (Begossi 2006).

The informal rules on boundaries between resorts are also quite clear: trespassing is OK, but not moving shacks on their territory; using their roads is OK, but only if it is reciprocated. But there are no clear rules for dealing with boundary conflicts. Emerging boundaries in the absence of neighbours were easy to manage, but neighbours with ambitions necessitated case-by-case solutions. A young resorter in an interview said: "it is OK now, but in the old days it could get rough when a new guy came in and wanted to expand".

In contrast with many examples analysed in institutional economics, there has been no gradual formal consolidation of rules of behaviour into explicit laws. Sugden (1989) stressed the importance of convention in the formation of spontaneous order in situations where formal rules are absent. The resort owners provide continuity in the organisation of activities on the lake and they are an important channel to pass on conventions. The Scandinavian heritage of both the ice fishing, practised there without fish houses, and a significant proportion of participants themselves stimulate the internalisation of conventions, such as the practice of maintaining relative silence and proper distance. The occasions are rare where you can have a good time while at the same time get in touch with your roots, engage with harsh surroundings, and build a self-regulating community from the bottom up.

Local governments, potentially a source of formalisation of institutions, were not seen as providing alternatives or threats. They were not seen as threats, as many political actors were associated with the ice fishing community. They were not seen as alternatives either, since these governments were usually rather weak and poor, and they were politically not inclined to interfere with business, with outdoors activities. The participants were not eager to enlist interference of governments and law enforcement agents in an intrinsically 
recreational activity. (This attitude occurred with virtually all fishermen, guides, resort owners and shop and bar owners - interviews.)

It is not that the actors were unaware of possible alternative forms of organisation; rather, they preferred the informal approach (Ostrom 1990). In the words of a bait shop owner: "better to lie low and take care of things simply". It left them with more flexibility as the new activity developed in unexpected directions. ${ }^{7}$ It also avoided a situation where future disputes would rely on formalised rules for resolution, while these rules ultimately refer to a basic institution that is informal, i.e. informal property.

\subsection{Network versus central steering}

What made the villages on the ice of lake Mille Lacs possible was an entwining of technological and institutional innovation. In turn, this was possible because of a network of players with shared goals. Resort owners are aware of their interdependence, given the special physical and institutional conditions (informality), and given their interdependence with other businesses and the fishermen themselves (who are more than 'customers'). This generalised awareness of interdependence functions as a catalyst for open innovation and the development of an 'ice civics' (Putnam 1993; Ostrom 2005). Thus the awareness of interdependence drove both institutional and technological development, and simultaneously worked as a stabiliser of the configuration of formal and informal institutions that sustained the villages (Hajer and Wagenaar 2003; Klijn and Skelcher 2007).

Questioning the legality of this or that aspect of ice fishing was perceived as jeopardising an industry and a community, a path nobody wanted to go down. Ice fishing inspired identification with the ice fishing community, and that community is conceived as a network of innovation and decision making, albeit with an important role for the resort owners. Network steering emerged naturally in this context of interdependence (Davies 2002; Hahn 2011), with central steering (in this case emanating from the resort owners) relegated to a limited set of issues: road construction, village layout and the regulations mentioned above.

Informality and network steering thus reinforced each other (two dimensions), while the physical conditions asked for a knowledge intensity that was delivered because of intense and open interactions between various innovating players (which works better in a network). Distribution of knowledge and risk management were also furthered by an aspect of central steering tied to the role of the resort owner. This again makes clear that the dimensions cannot be adequately understood as either/or choices. Governance arrangements can be marked by aspects of each, and positions on particular choice dimensions can lie in between polar cases.

\subsection{Participatory versus representative democracy}

Considering the distinction between participation and representation in enacting or supervising environmental governance, decision making on the ice is participatory in many ways, even though there are no formal institutions of participation (in contrast with most of the cases in the literature). In line with the informality of institutions, there are no clear rules of participation nor representation, only a network with a continuous flow of information and with actors readily moving between roles to facilitate adaptation and innovation. Thus, one could say that this distinction is of lesser importance here.

It does become relevant where ice fishing activities interact with other aspects of society. Even though governance on the ice is only embedded weakly within the formal 
governance structures of the surrounding areas, these structures are sometimes felt. Interviewees reported a few incidents of police intervention; when fights between fishermen got out of hand, when competition between resorts got a bit rowdy, and on a few occasions this area of marginal law enforcement was used for drugs trade. (The larger confrontation with the Mn-DNR after the native American court case had a more lasting impact and is discussed in greater detail below.) We argue that the key question in this situation is not so much whether participation undermines representation (Helmke and Levitsky 2004; Klijn and Skelcher 2007), but whether the informal policies on the ice undermine the mix of participation and representation emanating from higher levels of government (Anderson 1999; Young 2002; Hahn 2011). One can pose the question in reverse, i.e. whether the broader formal environment can continue to tolerate the informalities on the ice (Ellickson 1991; Ledeneva 2006; Rosen 2008). This interaction became especially important when an external shock affected ice governance. Below, we discuss the resumption of fishing by native American tribes and the more stringent catch restrictions consequently imposed by the Mn-DNR.

One element of representative democracy is suggested by the importance of the resort owner, an actor with a profit motive, but with a wider authority accepted by others. His role mixes political and economic institutions. The resort owners are not elected by the fishermen, but they are acknowledged by all as being responsible for and deciding organisational aspects of the ice fishing villages. This includes, for example, implementing measures to enhance safety on the roads or in the neighbourhoods, deciding on the layout of the neighbourhoods, arbitrating disputes, etc. They also represent the fishermen's interests in their absence, e.g. when dealing with government actors. (Some owners have such representation clauses in the contracts their customers sign.)

However, the (circumscribed) profit motive of the resort owner erodes the meaning and autonomy of both forms of democracy (configurations of political institutions). Indeed, economic institutions are always embedded in political institutions, but in a democracy they are also differentiated, i.e. political actors are supposed to be driven by a political logic, while an economic logic applies to economic actors (Acemoglu and Robinson 2012). One could speak of partial privatisation, although only partial, since others see the profit making of the resorters as necessary to the survival of the whole community. It is an accepted and intermediate goal of governance, and not the only one.

Therefore, it can be said that informality and network steering dominate, yet elements of central steering by resorters are accepted. This delegated power (representation) of the resort owners is tied to a role that is not merely political and not merely economic. Physical conditions and the preferences of other actors lead to a mixed role for the resort owner. The existence of an actor who can manage risk, offer infrastructure, and mediate/disseminate the learning in the network, is accepted, even desired, even if this is limiting the scope of democracy in the network. Therefore, this mixing of politics and economics in the figure of the resorter introduces an element of central steering, of representation, but it also supports the reproduction of the networks of steering and innovation. The linkages between choice dimensions multiply.

\subsection{Local versus scientific knowledge}

It was and is believed by virtually all players that the path of innovation that was taken increased the scale, quality and sustainability of the ice fishing industry. It is believed that all profited from the insistence on bounded competition, strong 
co-operation and open innovation. This institutional configuration thus encouraged fast development of and reliance on local knowledge, but that local knowledge cannot be simply opposed to scientific knowledge (Davidson-Hunt 2006; Berkes 2009; Singh, Pretty, and Pilgrim 2010). Scientific knowledge in this case is not uniquely associated with government, with industry or with Western modernity, but is also generated through local experimentation.

The reinstatement of native American fishing rights, discussed in greater detail below, required a new form of monitoring that was directly linked to formal government. After the conflict, that government was perceived as not so much a neutral background, but a negative force, opposed to the ice fishing community. 'Science' became associated with a DNR that was now perceived as more oppressive, and the often scientific character of knowledge produced in the local network was not observed anymore: "We know better than those scientists how this lake works", claimed an old guide. It became a sport to find flaws in analyses and estimates produced by the DNR, and to question the utility and veracity of 'science'.

The local rhetoric about science (as related to government) belies the fact that science is omnipresent in the ice fishing communities, and that technical innovation is part and parcel of the experience of ice fishing - often the wait for a catch is long. Intense interaction between fishermen and other players, in a form of network steering, and in a context where many are interested in technique, made it possible for a process of continuous experimentation to emerge: "We always checked with the guys in other neighbourhoods, had a beer, see what they came up with" (old fishermen). Scientific and local knowledge blended in ways that were often imperceptible, a mix embodied in new technical tools and new techniques. (Similarly, engineering skills combine scientific and other forms of knowledge and experience.)

The resort owner, still regarded as 'one of us', does not simply exploit the network of innovation, but judiciously balances how he can contribute to and disseminate the innovations, while still making a living. For him, profit maximisation is not the only goal, and many resorters see themselves as 'one of them'. Informality smoothes the interactions, and hence learning and innovation, in this situation of fluid roles. The fact that life in the ice villages is seen as "not the real world" (old fishermen), makes it easier to maintain this particular coupling of informality, network/central steering, politics/ economics and scientific/local knowledge.

\subsection{Coupled dimensions and absorbing shocks}

We have hinted already at the lengthy legal battle, going all the way to the Supreme Court in 1999, that reconfirmed the fishing rights of the Ojibwe tribe mentioned in a 1837 treaty. ${ }^{8}$ Subsequently, the native Americans resumed their traditional ways of fishing, with nets during the spring. In combination with increased recreational fishing, as illustrated in Figure 2, the walleye population in the lake quickly declined. A different interaction with the lake's ecology was prompted and the Mn-DNR gradually tightened harvest restrictions for recreational fishing. The most important changes are listed in Table 2.

A first set of restrictions, introduced in 1997, was the reduction of the total number of walleye that could be caught and kept, and the introduction of a minimum harvest size. A size threshold was instated, and gradually raised, above which only a single fish could be kept. The most restrictive form of regulation was introduced in 1999, with the imposition of a harvest slot, requiring the release of any smaller or larger fish. The slot fluctuated in 
Table 2. Major changes in harvest regulations for walleye on Lake Mille Lacs (1985-2007).

\begin{tabular}{lcccc}
\hline Year & Max. catch & Size threshold & Harvest slot & Protected slot \\
\hline 1985 & 6 & Only 1 over 20" & & \\
1997 & 4 & Minimum 15" & \\
1999 & & Only 1 over 26" & $14 "-20 "$ & \\
2000 & & $14 ”-18 ”$ & \\
2001 & & $16 "-20 "$ & \\
2002 & & $14 "-16 "$ & \\
2003 & & none & $17 "-28 ”$ \\
2004 & & & $20 "-28 "$ \\
\hline
\end{tabular}

Note: In some years the regulations were slightly relaxed or tightened as the season progressed.

Source: Mille Lacs Lake Creel Survey Report, Completion Report, Minnesota, Study 4, Jobs 748, 780

(Jones, 1982-2007).

size between 1999 and 2002 and was often adjusted during the season. In 2003, it was replaced by a protected slot which specified, instead, which fish could not be harvested.

The regulations had a different impact on summer and ice fishing. In the summer season, catch rates are much higher and fishermen had the luxury of targeting larger fish. As a result, the introduction of a harvest slot was felt as highly restrictive in the summer, although survey evidence suggests that compliance was very good. For walleye exceeding 20 inches, the release rate immediately jumped from an average of around $25 \%$ prior to 1997 to almost $100 \%$ (dotted line in Figure 4). It was a lucky coincidence that the introduction of the harvest restrictions was followed by a few years with unusually high catch rates, which made the sport attractive even without taking a catch home. The DNR surveys indicate that the vast majority of releases of large walleye were voluntary in the summer season (on average 90\%), but this also changed suddenly with the new regulations. Release rates were extremely low when harvesting walleye in the 15-16.9 inches slot was allowed again in 2003 (at 8.2\%), or when the permissible range was expanded to the 16-19.9 inches range in 2004 (at 7.1\%).

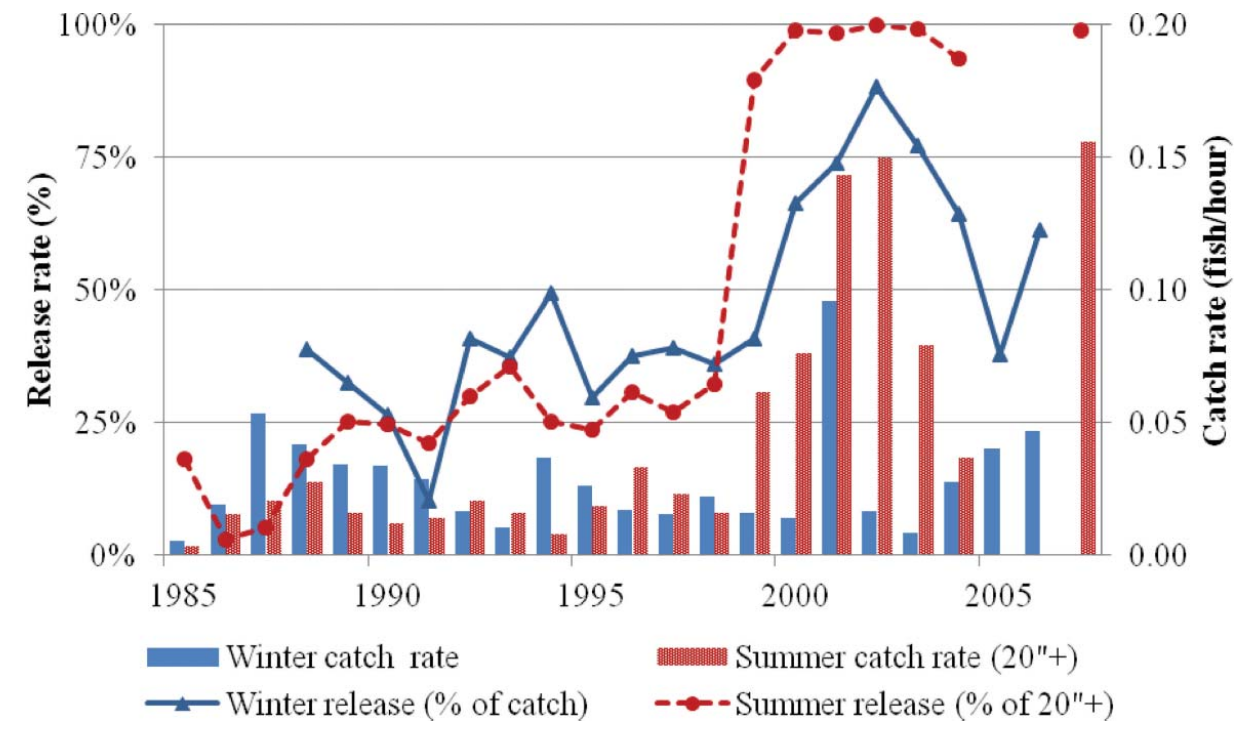

Figure 4. Evolution of release rates ( $\%$ of catch) and catch rates (fish per hour) for walleye. 
In contrast, release rates in the winter season have trended up much more gradually (solid line in Figure 4). When fishing pressure on the lake increased, voluntary adjustment was more important than in the summer, but at the same time compliance with the externally imposed regulations was not as good. The re-opening of the 15-16.9 inches slot in 2003 and the 16-19.9 inches slot in 2004 led to voluntary release rates of $21 \%$ and $13 \%$. These are more than double the comparable statistics over the winter season, even though overall catch rates only averaged 0.02 walleye per hour in the ice fishing season. It suggests that ice fishing is less driven by the goal of taking a price home and more focused on the activity itself. At the same time, the heavy-handed introduction of regulations by the Mn-DNR created a lot of resentment. It resulted in a larger decline in fishing hours over the winter than over the summer season (see Figure 2).

The shock also influenced governance on the ice. While for a long time the mix of participation and representation that marked the surrounding territories had little effect, the system of representation in the wider environment - in particular the forced delegation of power to the court system - did shake up and transform governance of the ice villages. Clearly, it was not as isolated from the institutional environment as many local players thought (Berkes 2002). A positive interpretation of the situation is that the merits of representative democracy (including separation of powers) are still tangible on the ice, and that the ice institutions did not undermine the representative institutions (in line with most observations of Klijn and Skelcher 2007 and Hahn 2011, but also in line with the institutionalist literature, e.g. Eggertsson 2005 and Ostrom 2005).

A negative interpretation would be that informal governance networks cannot be entirely stable in a larger environment marked by formality and representation (something seemingly overlooked by Hajer and Wagenaar 2003 and early networksteering advocates). We believe it is fair to say that, after a period of anger and resistance, the same network that mobilised resistance also made it easier to adapt to the new situation (Olsson, Folke, and Berkes 2004) and to find new ways to make ice fishing palatable for all. The emphasis moved to mobile adventurous fishing, catch-and-release, cameras and activity packages. An old fisherman stated: "the young guys (resorters) figured out how to make it fun for the whole family again, and for other young guys".

The response to the shock shows the resilience of the local governance arrangement and it shows in a much shorter time frame, compared to the emergence of the villages, how dimensions interrelate.

\section{Configurations: towards evolutionary governance theory}

In the case of the Mille Lacs ice villages, the harsh conditions and specific ecology required technical innovation, in a mix of scientific and other knowledge that became local. The lack of existing local organisations and the legal vacuum resulting from the absence of formal property rights required the invention of organisations and rules. Organisations could be formal, but not the rules, since ownership of the ice that was formally impossible. Nobody could do it by themselves, so a network of actors developed. In that network, people changed roles and combined roles. The resorts were accepted as major players but were still part of a network of learning, adaptation and law enforcement. Resorts became the main actors because they could start from existing organisations (summer resorts), endowed with important local knowledge, political connections, access control and investment capacity (Milgrom, North, and Weingast 1990; Greif 2007; Van Assche et al. 2011). 
Once crystallised, the actor of the resort channelled the reproduction of the governance network and its institutions (Folke et al. 2005; Czarniawska 2008; Van Assche, Verschraegen, and Salukvadze 2010), but neither individual resorts nor the group of resort owners could take binding decisions for all the other players. An awareness of community, of interdependence, made the network tight, simultaneously increasing the effects of actors on each other and maintaining their autonomy (Seidl 2005). The awareness of interdependence excluded the option of single dominance and direct steering (Ostrom 1990).

The choice for informality emerged out of local physical and institutional conditions, and some of these conditions made it virtually impossible to revert to formality. The requirements of the locale, of the sport, and the earlier presence of resort owners, fishermen, fishing guides, bait shop owners rendered them the core of a tightly knit network, where interdependence produced innovation and required network steering. New players were added over time, such as producers of equipment, themselves a product of the network. Informality here did not link up with reliance on local knowledge as opposed to scientific knowledge, and it did not translate into a form of participatory governance, at least when this is understood as formalised procedures of shared decision making. Meanwhile, the largely representative democracy in the state of Minnesota cannot give full autonomy to the self-organisation on the ice.

This summary of the evolution of governance on Mille Lacs highlights the most important local couplings between the choice dimensions that were initially distilled from the literature: forms of democracy, steering form, institutions and knowledge mobilisation. In our model, power and knowledge shape each other; and actors and institutions shape each other. Governance evolves and all elements are shaped by a history of interactions. The ice villages represent one pathway in which a specific set of couplings formed and remained relevant for the continuous reproduction of governance (Van Assche, Beunen, and Duineveld, forthcoming). For the Mille Lacs case, the positions on each of the crystallised choice dimensions, their co-evolution and responsiveness to change appear logical in the conceptual governance model presented earlier, but the case also suggests several extensions to the model. We list three:

- Dimensions should not be understood as simple polarities. A particular situation can have aspects of each side of a distinction, as the complexity of governance arrangements allows for the coexistence of several positions on each scale. Even where institutions, actors, knowledge and power relations were apparently created from scratch, the emerging configurations are not unified, cohesive, to the extent that single choices induce single choices elsewhere. The interaction of dimensions raises the complexity, but also the flexibility and adaptivity of governance (Czarniawska 2008; Berkes 2009).

- Scale matters: The ice is not an entirely autonomous region. What happens there does not always stay there. The frozen lake is part of Minnesota, which is part of the US, and the configurations of power/knowledge and actors/institutions on those scales delineate the scope of autonomous governance that is possible on the lake. To some extent, the governance of the villages reflects an American tradition of privatisation of the commons, but to some extent it also has to be understood as a counter-world, where actors can behave differently from their daily lives. Governance evolutions are thus to be understood as nested evolutions (cf. Berkes 2002; Hahn et al. 2008). 
- Identity matters: On the ice, a shared identity aids the functioning of an interdependent community. It supports the precarious balance between privatisation and democratic governance, between central steering and network steering (Easterly 2006; Ledeneva 2006; Van Assche et al. 2011; Acemoglu and Robinson 2012). It makes the coexistence possible of an open innovation network and profit-making resorters making a living on the ice. The role of social identities merits closer evaluation.

An evolutionary model revealing contingent co-evolution of configurations and choice dimensions can help people with diverse interests to evaluate governance arrangements, and to delineate intervention options. Similar to North (2005), Easterly (2006) and Acemoglu and Robinson (2012), we believe that focusing on single dimensions or parameters of governance, and/or focusing on norms and goals without sufficient analysis of evolutionary mechanics is bound to inspire social engineering aspirations and formulaic policy prescriptions that are doomed to fail.

\section{Notes}

1. Shanties did show up simultaneously on a few other lakes in the upper Midwest and the North Eastern United States, but in far smaller numbers and not in villages (Chiapetta 1966; Griffin 1985).

2. The total number of fishing hours during the winter season exceeded total hours in the summer season by more than $50 \%$ in 11 of 29 years for which we observed fishing hours in both seasons.

3. Before the adoption of sonar based electronics, simpler devices were used to measure depths.

4. A resort owner described the use of a wooden plank with various pencil markings fitted to the dashboard of his truck, to read horizon markers more accurately.

5. Kaffine (2009) described a similar arrangement in California, where local surfers claim and enforce de facto ownership of surf breaks even though formal ownership is impossible.

6. This argument is similar to the standard reasons why it becomes more difficult to sustain collusion in an oligopoly when the discount factor rises. Cabral $(2000,130)$ discussed several reasons why the discount factor will depend on features of industry evolution: growth of demand, likelihood of exit, frequency of interaction, etc.

7. The heavy-handed imposition of harvesting regulations by the Mn-DNR after 1997 (discussed later) strengthened the view of participants we interviewed that the initial choice to rely solely on informal organisation in the development of the industry had been the right one.

8. The legal dispute between the state of Minnesota and the Ojibwe tribe of native Americans (between 1990 and 1999) eventually concluded with the Mn-DNR losing jurisdiction over native American fishing.

\section{References}

Acemoglu D., and J. Robinson. 2012. Why Nations Fail: The Origins of Power, Prosperity and Poverty. New York: Random House.

Agrawal, A., and C. Benson. 2010. "Common Property Theory and Resource Governance Institutions: Strengthening Explanations of Multiple Outcomes." Environmental Conservation 38 (2): 199-210.

Agrawal, A., and A. Chhatre. 2011. "Against Mono-Consequentialism: Multiple Outcomes and their Drivers in Social-Ecological Systems." Global Environmental Change 21: 1-3.

Agrawal, A., and C. Gibson. 1999. "Enchantment and Disenchantment: The Role of Community in Natural Resource Conservation." World Development 27: 629-649.

Allen, P. M. 2001. "A Complex Systems Approach to Learning in Adaptive Networks." International Journal of Innovation Management 5: 149-180.

Anderson, L. 1999. Transitions to Democracy. New York: Columbia University Press. 
Begossi, A. 2006. "Temporal Stability in Fishing Spots: Conservation and Co-Management in Brazilian Artisanal Coastal Fisheries." Ecology and Society 11 (1): 15.

Berkes, F. 2002. "Cross-Scale Institutional Linkages for Commons Management: Perspectives from the Bottom Up." In The Drama of the Commons, edited by E. Ostrom, T. Dietz, N. Dolsak, P. C. Stern, S. Stonich, and E. U. Weber, 293-321. Washington, DC: National Academy Press.

Berkes, F. 2009. "Evolution of Co-Management: Role of Knowledge Generation, Bridging Organizations and Social Learning." Journal of Environmental Management 90: 1692-1702.

Booher, D. E., and J. E. Innes. 2010. "Governance for Resilience: CALFED as a Complex Adaptive Network for Resource Management.” Ecology and Society 15 (3): 35.

Breining, G. 2003. Fishing Minnesota. Angling with the Experts in the Land of 10.000 Lakes. Minneapolis: University of Minnesota Press.

Breining, G., and L. Kennedy. 2008. A Hard-Water World: Ice Fishing and Why We Do It. St Paul: Minnesota Historical Society Press.

Bulkeley, H., and A. Mol. 2003. "Participation and Environmental Governance: Consensus, Ambivalence and Debate." Environmental Values 12: 143-154.

Cabral, L. M. B. 2000. Introduction to Industrial Organization. Cambridge, MA: MIT Press.

Chiapetta, J. 1966. Ice Fishing. Harrisburg: Stackpole Books.

Czarniawska, B. 2008. A Theory of Organizing. Cheltenham: Edward Elgar.

Dalrymple, B. 1948. Ice Fishing: For Everybody. New York: Lantern Press.

Davidson-Hunt, I. 2006. "Adaptive Learning Networks: Developing Resource Management Knowledge Through Social Learning Forums.” Human Ecology 34 (4): 593-614.

Davies, A. 2002. "Power, Politics and Networks: Shaping Partnerships for Sustainable Communities." Area 34: 190-203.

Easterly, W. 2006. The White Man's Burden: Why the West's Efforts to Aid the Rest Have Done So Much Ill and So Little Good. London: Penguin.

Eggertsson, T. 2005. Imperfect Institutions: Possibilities and Limits of Reform. Ann Arbor: University of Michigan Press.

Ellickson, R. 1991. Order Without Law. Cambridge, MA: Harvard University Press.

Farrell, H., and Héritier, A. 2003. "Formal and Informal Institutions Under Codecision: Continuous Constitution-Building in Europe." Governance 16: 577-600.

Fellegy, J. 1973. Walleyes and Walleye Fishing. Minneapolis: Dillon Press.

Fellegy, J. 1990. Mille Lacs: Thirty Years on the Big Lake. Aitkin: Mille Lacs Press.

Fernandez-Gimenez, M. E., H. L. Ballard, and V. E. Sturtevant. 2008. "Adaptive Management and Social Learning in Collaborative and Community-Based Monitoring: A Study of Five Community-Based Forestry Organizations in the Western USA." Ecology and Society 13 (2): 4.

Folke, C., T. Hahn, P. Olsson, and J. Norberg. 2005. "Adaptive Governance of Social-Ecological Systems." Annual Review of Environmental Resources 30: 441-473.

Greif, A. 2007. The Path to Economic Development: Lessons from Medieval Trade. Cambridge: Cambridge University Press.

Greif, A., P. Milgrom, and B. R. Weingast. 1994. "Coordination, Commitment, and Enforcement: The Case of the Merchant Guild." Journal of Political Economy 102 (4): 745-776.

Griffin, S. 1985. Ice Fishing: Methods and Magic. Harrisburg: Stackpole Books.

Hahn, T. 2011. "Self-organized Governance Networks for Ecosystem Management: Who is Accountable?" Ecology and Society 16 (2): 18.

Hahn, T., L. Schultz, C. Folke, and P. Olsson. 2008. "Social Networks as Sources of Resilience in Social-Ecological Systems." In Complexity Theory for a Sustainable Future, edited by J. Norberg and G. Cumming, 119-148. New York: Columbia University Press.

Hajer, M., and H. Wagenaar. 2003. Deliberative Policy Analysis: Understanding Governance in the Network Society. Cambridge: Cambridge University Press.

Helmke, G., and S. Levitsky. 2004. "Informal Institutions and Comparative Politics: A Research Agenda." Perspectives on Politics 2 (4): 725-740.

Jones, T.S. 1982-2007. Mille Lacs Lake Creel Survey Report: Completion Report. St Paul, MN: Minnesota Department of National Resources.

Kaffine, D. T. 2009. "Quality and the Commons: The Surf Gangs of California." Journal of Law and Economics 52 (4): 727-743.

Keen, M., S. Mahanty, and J. Sauvage. 2006. "Sustainability and Local Government: Achieving Innovation Through Practitioner Networks." Local Environment 11: 201-216. 
Kernick, D. P. 2005. "Facilitating Resource Decision Making in Public Organizations Drawing Upon Insights From Complexity Theory.” Emergence: Complexity and Organization 7: 2-10.

Kickert, W. J. M., E. Klijn, and J. F. M. Koppenjan. 1997. Managing Complex Networks: Strategies for the Public Sector. London: Sage.

Klijn, E-H., and C. Skelcher. 2007. "Democracy and Governance Networks: Compatible or Not?" Public Administration 85 (3): 587-608.

Ledeneva, A. V. 2006. How Russia Really Works: The Informal Practices that Shaped Post-Soviet Politics and Business. Ithaca: Cornell University Press.

Lindner, A., D. Stange, and D. Genz. 1991. Ice Fishing Secrets. Brainerd: In-Fisherman.

Luhmann, N. 1990. Political Theory in the Welfare State. Frankfurt: Opladen.

Lyback, P. 1996. Fifty Thousand Holes. Sioux Falls: Pine Hill Press.

Margerum, R., and D. Whitall. 2004. "The Challenges and Implications of Collaborative Management on a River Basin Scale." Journal of Environmental Planning and Management 47: 409-429.

Milgrom, P. R., D. C. North, and B. R. Weingast. 1990. "The Role of Institutions in the Revival of Trade: The Law Merchant, Private Judges and the Champagne Fairs." Economics and Politics $2(1): 1-23$.

Milgrom, P. R., and J. Roberts. 1990. "The Economics of Modern Manufacturing: Technology, Strategy and Organization." American Economic Review 80 (3): 511-528.

Newig, J., D. Gunther, and C. Pahl-Wostl. 2010. "Synapses in the Network: Learning in Governance Networks in the Context of Environmental Management." Ecology and Society 15 (4): 24.

Nordstrom, K. 2007. The Fish House Book: Life on Ice in the Northland. Duluth: Dovetailed Press.

North, D. 1990. Institutions, Institutional Change and Economic Performance. Cambridge: Cambridge University Press.

North, D. 2005. Understanding the Process of Economic Change. Princeton: Princeton University Press.

Olsson, P., C. Folke, and F. Berkes. 2004. "Adaptive Co-Management for Building Resilience in Social-Ecological Systems.” Environmental Management 34 (1): 75-90.

Ostrom, E. 1990. Governing the Commons: The Evolution of Institutions for Collective Action. Cambridge: Cambridge University Press.

Ostrom, E. 2005. Understanding Institutional Diversity. Princeton: Princeton University Press.

Putnam, R. 1993. Making Democracy Work: Civic Traditions in Modern Italy. Princeton: Princeton University Press.

Rosen, L. 2008. Law as Culture: An Invitation. Princeton: Princeton University Press.

Seidl, D. 2005. Organizational Identity and Self-Transformation. Aldershot: Ashgate.

Singh, R., J. Pretty, and S. Pilgrim. 2010. "Traditional Knowledge and Biocultural Diversity: Learning from Tribal Communities for Sustainable Development in Northeast India." Journal of Environmental Planning and Management 53 (4): 511- 534.

Smith, S. C. 2001. Brainerd Mille Lacs Area: Fishing Guide. St Paul, MN: Fins Press.

Stark, L., and M. Berglund. 1990. Hook, Line and Shelter: Ice Fishing Tales and Photos Too. Cambridge, MN: Adventure.

Sugden, R. 1989. “Spontaneous Order.” Journal of Economic Perspectives 3 (4): 85-97.

Van Assche, K., R. Beunen, and M. Duineveld. (forthcoming). Evolutionary Governance Theory: An Introduction. Heidelberg: Springer.

Van Assche, K., R. Beunen, J. Jacobs, and P. Teampau. 2011. "Crossing Trails in the Marshes: Flexibility and Rigidity in the Governance of the Danube Delta." Journal of Environmental Planning and Management 54 (8): 997-1018.

Van Assche, K., G. Verschraegen, and J. Salukvadze. 2010. "Changing Frames: Expert and Citizen Participation in Georgian Planning." Planning Practice and Research 25 (3): 377-395.

Verdery, K. 2003. The Vanishing Hectare. Ithaca, NY: Cornell University Press.

Williamson, O. E. 1981. "The Economics of Organization: The Transaction Cost Approach." American Journal of Sociology 87 (3): 548-577.

Young, O. 2002. The Institutional Dimensions of Environmental Change: Fit, Interplay and Scale. Cambridge: Cambridge University Press. 